\title{
Effect of Ergonomic Hazards on Job Performance of Auditors in Nigeria
}

\author{
Omoneye 0. Olasanmi \\ Department of Management and Accounting, Obafemi Awolowo University, Ile-Ife, Nigeria \\ Email: neyeolasanmi@yahoo.com
}

Received 25 November 2015; accepted 23 January 2016; published 26 January 2016

Copyright (C) 2016 by author and Scientific Research Publishing Inc.

This work is licensed under the Creative Commons Attribution International License (CC BY). http://creativecommons.org/licenses/by/4.0/

(c) (i) Open Access

\begin{abstract}
This study examined ergonomic hazards which are associated with auditors' job and the effects on performance of auditors. Primary data were collected from auditors of "Big Four" auditing firms in Nigeria via administration of questionnaire from 825 respondents. Descriptive and inferential statistical tools were used to analyse the primary data. The results of this study identified several hazards were associated with an auditor's job. Top on the list of the hazards is headache, as opined by $56.9 \%$ of the respondents and $54.5 \%$ of the respondents reported inadequate sleep. It was revealed that neck pain $\left(\chi^{2}=12.894 ; p<0.05\right)$, wrist pain $\left(\chi^{2}=9.138 ; p<0.05\right)$ and inadequate sleep $\left(\chi^{2}=8.276 ; p<0.05\right)$ were most prevailing hazards linked with auditors job. It is also revealed that an insignificant relationship exists between ergonomic hazards and performance $\chi^{2}=4.763 ; p=$ 0.312).
\end{abstract}

\section{Keywords}

Ergonomic Hazards, Auditor, Job Performance

\section{Introduction}

The introduction of technology in the workplace may cause organizations to suffer from a "combination of technology fatigue and aversion” resulting in ergonomic hazards such as headache, neck pain, wrist pain, and visual fatigue [1]. This dependence on technology has resulted in several ergonomic hazards ranging from headaches, eye strain, and blurred vision, to tingling, numbness, and pain in the neck, back, shoulder, elbow, wrist, or hand. They in turn lead to dissatisfaction, fatigue and anxiety, negative self-evaluation, and avoidance towards technology [2]-[4]. It has been discovered that high performance (requirements) with high technology can exercise a dangerous influence on human personality and that anyone who is constantly working or playing with computers is at risk [2]. Ergonomic hazards linked to the usage of technological equipment often go unno- 
ticed until the user experience some discomfort. This is because such hazards usually occur gradually over a long period of time. According to [5] who carried out a study on technostress in the workplace, it was discovered that a certain percentage of the employee workforce who made use of computers experienced pain in the neck, back, hand, arm, tingling, numbness and exhaustion. This was supported by [6] who also discovered that the largest increase in back-ache was seen among computing professionals and technicians. Ergonomic hazards experienced by auditors on organisational performance have not been given much attention in Nigeria.

Previous researches ergonomic hazards have examined their impact on such variables as loyalty, efficiency and commitment in different industries. They include the telecommunications industry [7]-[9], education industry [10]-[16], and manufacturing industry [17]. However, empirical research in professional services industry such as public accounting firms, where information and knowledge play very prominent roles, have been very few.

Furthermore, earlier studies focused on the identification of factors that encouraged technology use. They produced a long list of items that proved to be of little practical value [18]. Also, a large number of researches have been done in different areas revealing the stressful aspects of technology however, the actual discussion about the role of modern technology as a source of stress is limited [19]. This research has thus spawned the desire to establish in practical terms, the factors which influence technostress and how these factors can affect performance within auditing firms. Examining the role of ergonomic hazard on users' performance signifies a new step which will lead to a better understanding by managers in different organisations of what has been reported in the literature and open a new path in this study among auditors and even accountants.

Job performance as defined by [20] is the execution of a task in a situation that allows optimal outcome. It is also defined as the ability of an employee to achieve the organisation's criteria [21]. Employees are regarded to achieve good performance when they meet up with the set goals and objectives of an organisation and as such, individual job performance could have a great influence on an organisation's overall performance. Hence, individual job performance is very important for organisational survival and can be considered the most important job outcome, especially for organisations or companies that have a high investment in human capital, such as auditing firms [22]. Furthermore, as any one individual is different from other individuals in terms of ability and personality, most companies tend to evaluate employees based on their individual job performance [22].

In auditing, individual job performance is very important and must be handled appropriately since it affects the quality of audits [22]. Compromises with job performance may produce substandard audit quality and consequently lead to potential legal liabilities and loss of credibility for the audit firms [23].

\section{Research questions}

1) What are the ergonomic hazards associated with technostress?

2) In what way can technostress and ergonomic hazards affect performance within an organization?

3) What are the strategies an individual or organization can adopt in order to minimize or alleviate technostress?

4) What influence do socio-demographic variable have on technostress and ergonomic hazards?

\section{Research objectives}

1) To determine the ergonomic hazards which are associated with auditors' job;

2) To determine the effects of techno stress and ergonomic hazards on performance of auditing firms.

\section{Research hypothesis}

1) There is no significant relationship between ergonomic hazards and performance among auditors.

2) There is no significant relationship between technostress and ergonomic hazards among auditors.

\section{Research Methodology}

\subsection{Area of Study}

The study was conducted in Lagos State, Nigeria. The selection of this state is based on the fact that most auditing firms in this survey have their headquarters located in Lagos. Lagos, as a commercial nerve centre, has attracted immigrants from all over Nigeria and beyond. Many of the country's financial institutions are located in the state and more than half of Nigeria's industrial capacity is located in Lagos' mainland suburbs. The firms sampled are Akintola Williams Deloitte, PricewaterhouseCoopers (PwC), KPMG, and Ernst \& Young. These firms are selected because combined 2011 market revenue for the four firms rose to historic high levels of \$103 billion ( 16 trillion), up 9\% from 2010, and surpassing the previous records earlier targeted for the firms. They 
are the four major auditing firms in Nigeria, referred to as the "Big Four" [24]. They are also registered with the Institute of Chartered Accountants of Nigeria (ICAN), which is the professional body regulating the activities of accountants and auditors in Nigeria.

Akintola Williams Deloitte is the oldest indigenous firm in Nigeria, established in 1952. Through astute management, the firm has grown in size and scope of services to become the largest professional services firm in Nigeria. The firm started operations in Nigeria as Akintola Williams \& Co. in 1952. Between April 1999 and May 2004, two mergers with existing accounting firms were consummated which resulted in its being the largest professional services firm in Nigeria with a staff of over 600. The firm adopted the business name "Akintola Williams Deloitte" on July 30, 2004. Akintola Williams Deloitte is part of Deloitte's West and Central Africa cluster, which is a member firm of Deloitte Touche Tohmatsu, an organization of member firms devoted to excellence in providing professional services. They are focused on client service through a global strategy executed locally in over 140 countries. With access to intellectual capital of 170,000 people worldwide, the organization delivers services in four professional areas of audit, tax, consulting, and financial advisory services.

$\mathrm{PwC}$ is a leading global network of audit and assurance firms, which helps companies improve their corporate reporting and provides assurance that their systems are operating effectively within a well-controlled environment. The organization's audit approach is tailored to suit the size and nature of different organizations and draws upon its extensive industry knowledge. The organization are leaders in the development of non-financial performance reporting, helping clients respond to the need for greater transparency, improved corporate governance, and business models based on the principles of sustainability.

KPMG Professional Services is the KPMG member firm in Nigeria. The partners and people have been operating in Nigeria since 1978, providing multidisciplinary professional services to both local and international organizations within the Nigerian business community. KPMG focus is to turn knowledge into value for the benefits of its clients and the capital markets. KPMG is committed to working with clients and cutting through complexities, finding solutions and adding value. As one of the leading providers of professional services, KPMG knows that the success and growth of the firm also depends on the success and growth of the Nigerian economy. Hence, it champions progressive change and makes the future happen for its clients, people and the community, thereby enabling Nigeria's success. The firm has a full complement of 23 partners and over 700 trained and dedicated professional staff; with deep industry skills and competencies in audit, tax and advisory services.

Ernst \& Young is a global leader in assurance, tax, transaction and advisory services. Worldwide, its 152,000 people are united by our shared values and an unwavering commitment to quality. The organization makes a difference by helping its people, clients and wider communities achieve their potential. "Ernst \& Young" refers to the global organization of member firms of Ernst \& Young Global Limited ("EYG”), each of which is a separate legal entity.

\subsection{Data Collection Techniques}

Data for this study will be collected from primary sources. The data will be sourced from a carefully constructed questionnaire, which will be distributed among four (4) major auditing firms which are registered with the Institute of Chartered Accountants of Nigeria (ICAN). These are referred to as the "Big Four"; they are Akintola Williams Deloitte, PricewaterhouseCoopers, KPMG, and Ernst \& Young. Auditors, who will serve as respondents, will thus be selected from each of these firms.

\subsection{Population, Sample Size and Sampling Procedure}

The population for this study consists of staff members in the Audit Departments of the "Big Four" (Akintola Williams Deloitte, PricewaterhouseCoopers, KPMG, and Ernst \& Young). The "Big Four" are the four largest professional services networks in accountancy and professional services, offering services including Audit, Assurance, Tax, Consulting, Advisory, Actuarial, Corporate Finance and Legal. They handle the vast majority of audits for publicly traded companies as well as many private companies [24].

Auditors in the Audit Departments of the "Big Four" will be strictly selected for this study. This is because auditors require competence in information technology (IT), which is crucial for the professional accountant due to its pervasive use in the business world. Today, almost every aspect of the accounting profession is being pervasively affected by advances in IT [25], auditing not exempted. The extent, mode and quality of IT adoption in most enterprises are becoming more sophisticated and complicated, hence IT introduces new challenges and 
risks to the professional accountants [26]. Undoubtedly, in the light of large scale business failure around the world, one of the most critical roles is auditing (Ismail and Abidin, 2009). To be effective, auditors need to embed technology in everything they do during the audit process [27] [28]. The increasing dependence of businesses on computerized information systems requires auditors to evaluate their performance in spite of the stress associated with the work. This is important as audit judgment influences the quality and effectiveness of audit. From the information obtained from the Human Resource Department of each of the Big Four, the range of staff members in the Audit Section of KPMG, Akintola Williams Deloitte, PwC, and Ernst \& Young are 420 - 450, 380 - 400, 350 - 400 and 330 - 400 respectively. Taking the upper limits of each of the firms, that is, 450, 400, 400, and 400 , the population is thus 1650 . Simple random sampling technique will be used in selecting 225 out of 450 staff in KPMG, 200 out of 400 staff from Akintola Williams Deloitte, 200 out of 400 staff in PwC, and 200 out of 400 staff in Ernst \& Young; totalling 825 out of 1650 staff of the selected firms with a sample fraction of $50 \%$.

\subsection{Measurement of Variables}

The dependent variable, performance, will be measured using variables such as quality of work, how much of auditing work is accomplished, meeting up with deadlines, etc, based on constructs validated by [29]. In this study, Choo's measure has been slightly modified to accommodate more variables. The independent variables are technostress and ergonomic hazards. Technostress will be measured on the Technostress Scale as identified and validated by [4], this instrument will be modified to include more appropriate variables. Ergonomic hazards on the other hand will be measured using the Ergonomic Hazard Assessment Instrument developed by [30].

All the above scales adopted in this study were revised, amended, improved upon and finalized according to the result of pilot test.

\subsection{Research Instrument}

A carefully constructed questionnaire will be used as research instrument for this study. The questionnaire will consist of two sections. Section A will consist of items on demographic data of the respondents. Section B consists of items constructed in a closed-ended format to examine the ergonomic hazards associated with technostress.

\subsection{Validation of Research Instrument and Testing}

A structured questionnaire was developed from existing instruments and viewed in the light of the objectives of the research, its relevance, and the adequacy of the questionnaire items, in order to ensure the validity and reliability of the measures. To further find out how reliable the questionnaire is, a pre-test was carried out repeatedly under similar conditions to determine its consistency of measure. This helped in rephrasing questions that were not well structured originally, so as to generate appropriate answers. The instrument was thus finalized after a pilot test had been carried out. The result reliability using Cronbach's reliability was 0.77.

\subsection{Data Analysis Technique}

Data obtained from this study will be analyzed using both descriptive and inferential statistical tools. The data will be analyzed with SPSS package. Frequency tables, graphs, pie charts, and simple percentage analysis will be used to assess the level of technostress experienced among auditors (objective one), determine the ergonomic hazards which are associated with technostress (objective two), determine the role of technostress on performance (objective three), and identify the techniques or strategies which individuals and organizations can adopt in reducing technostress (objective four). The effect of socio-demographic variables on technostress and ergonomic hazards (objective five) will be examined using cross tabulations. The hypotheses of the study will be tested at 5\%, using Analysis of Variance (ANOVA), which will be used test for the relationship between technostress and performance, as well as the relationship between socio-demographic variables and technostress. Correlation analysis will be used to test for the relationship between ergonomic hazards and performance while the relationship between socio-demographic variables and ergonomic hazards will be tested using logistic regression analysis. 


\section{Data analysis and Results}

\subsection{Socio Demographic Information of Respondents}

From Table 1, 65.7\% of respondents were male, while 34.3\%, were female. This shows that the work of auditors was more dominated by the male gender. Majority of the respondents fall within the age brackets of 22 - 27 years (49.5\%) and 28 - 33 years (41.1\%). A few of the respondents (7.5\%) are within the age bracket of 34 - 39 years while only 16 respondents $(1.9 \%)$ out of a total of 825 , are above 40 years of age. This shows that a vibrant and younger age continuum dominate a larger percentage of the workforce. It was also observed that respondents have varied qualifications. Respondents with B.Sc degrees are 53.6\%. This is followed by HND degree holders (28.8\%), Mastersdegree holders (15.3\%) and OND degree holders (2.3\%).

\subsection{Determination of the Ergonomic Hazards Associated with Auditors' Job}

Several hazards have been found to be associated with an auditor's job. As depicted in Table 2, top on the list of the hazards is headache, which has a percentage of 56.9. This is followed by inadequate sleep, which was reported by $54.5 \%$ of the respondents. Low on the list are visual fatigue (16.9\%), back pain (15.9\%), neck pain (15.2\%), wrist pain (15.0\%), numbness in finger (12.1\%), poor posture (11.7\%), migraine (10.4\%), and depression (8.5\%). These hazards were claimed to be caused by poor lighting in office areas, poor screen resolution, poor screen positioning, inability to adjust monitor (for respondents who use a desktop), and inability to adjust chair height in the most appropriate angle. Others are difficulty to copy materials from the screen, lack of ability to take frequent breaks when tired, inability to use mouse pad while working on the computer, provision of chair without armrests, inappropriate size and shape of chair, and display screen being too close to sitting position.

\subsubsection{Significant of Ergonomic Hazard Intensity}

Table 2 shows a breakdown of the significant ergonomic hazard intensities associated with technostress. Out of the 825 respondents who participated in the study, 144 respondents recorded both the neck pain hazard and a level of technostress. More than eighty-six percent (86.3\%) of the respondents have high neck pain with high level of technostress, 57.1\% have a combination of moderate neck pain with high level of technostress, and 57.1\% also recorded low intensity neck pain with high level of technostress while $50.0 \%$ claimed that the combination of neck pain and technostress was non-existent. From the analysis, it was discovered that more of the auditors

Table 1. Distribution of socio-demographic of respondents.

\begin{tabular}{|c|c|c|c|}
\hline \multicolumn{2}{|c|}{ Socio-Demographic Data } & \multirow{2}{*}{$\begin{array}{c}\text { No. of Respondents (Frequency) } \\
542\end{array}$} & \multirow{2}{*}{$\begin{array}{c}\text { Percentage (\%) } \\
65.7\end{array}$} \\
\hline & Male & & \\
\hline \multirow[t]{4}{*}{ Sex } & Female & 283 & 34.3 \\
\hline & Total & 825 & 100 \\
\hline & $22-27$ & 408 & 49.5 \\
\hline & $28-33$ & 339 & 41.1 \\
\hline \multirow[t]{5}{*}{ Age } & $34-39$ & 62 & 7.5 \\
\hline & Above 40 & 16 & 1.9 \\
\hline & Total & 825 & 100 \\
\hline & Masters & 126 & 15.3 \\
\hline & B.Sc. & 442 & 53.6 \\
\hline \multirow[t]{3}{*}{ Qualification } & HND & 238 & 28.8 \\
\hline & OND & 19 & 2.3 \\
\hline & Total & 825 & 100 \\
\hline
\end{tabular}

Source: Field Survey, 2013. 
Table 2. Ergonomic hazards associated with auditors’ job. .

\begin{tabular}{|ccc|}
\hline Ergonomic Hazard & Frequency & Percentage (\%) \\
Headache & 469 & 56.9 \\
Inadequate Sleep & 450 & 54.5 \\
Visual Fatigue & 139 & 16.9 \\
Back Pain & 131 & 15.9 \\
Neck Pain & 125 & 15.2 \\
Wrist Pain & 124 & 15.0 \\
Numbness in Finger & 100 & 12.1 \\
Poor Posture & 96 & 11.7 \\
Migraine & 86 & 10.4 \\
Depression & 70 & 8.5 \\
\hline
\end{tabular}

Source: Field Survey, 2013.

(67.4\%) recorded a high level of technostress as compared with those with low level of technostress (32.6\%) due to neck pain. This implies that neck pain hazard among auditors is on the high side. A Pearson's Chi-Square test was carried out at a 0.05 level of significance to further find out if there is a significant relationship between neck pain hazard and the level of technostress among auditors. The result of the test shows that there is a significant relationship $\left(\chi^{2}=12.894 ; p<0.05\right)$ between neck pain as a hazard and technostress. This connotes that neck pain, which could be an adverse effect of strains from the usage of technological facilities, can lead to an increase in the level of technostress. This result is supported by [5], who claimed that more than $30 \%$ of employees who work at the computer experience neck pain. Also, according to [31], they claimed that $63 \%$ of the respondents in study on health hazards related to computer use attested to the fact that neck pain was one of the hazards experienced.

Table 2 also shows the relationship between wrist pain hazard and technostress associated with an auditor's job. 150 respondents recorded both the wrist pain hazard and a level of technostress. $54.4 \%$ of the respondents have high wrist pain with high level of technostress, $75.5 \%$ have a combination of moderate wrist pain with high level of technostress, $80.5 \%$ also recorded low intensity wrist pain with high level of technostress while $66.7 \%$ claimed that the combination of wrist pain and technostress was non-existent. A Pearson's Chi-Square test carried out at a 0.05 level of significance further revealed that there is a significant relationship between wrist pain hazard and technostress among auditors. This connotes that wrist pain, which could occur as a result of sprains from the usage of technological facilities, can lead to an increase in the level of technostress. This result was corroborated by [31] in a study on health hazards related to computer use. They claimed that $44.4 \%$ of the respondents encountered burning in the hands and wrists.

As revealed further in Table 2, 469 respondents recorded both the inadequate sleep hazard and a level of technostress. More than sixty percent (60.9\%) of the respondents have high inadequate sleep with high level of technostress, $49.0 \%$ have a combination of moderate inadequate sleep with high level of technostress, $50.0 \%$ recorded low inadequate sleep with high level of technostress while $0.0 \%$ claimed that the combination of inadequate sleep and technostress was non-existent. From the analysis, it was discovered that more of the auditors (52.5\%) recorded a high level of technostress as compared with those with low level of technostress (47.5\%). A Pearson's Chi-Square test was carried out at a 0.05 level of significance to further find out if there is a significant relationship between inadequate sleep hazard and the level of technostress among auditors.

\subsubsection{Non-Significant Relationships between Ergonomic Hazard Intensity and Level of Technostress}

Table 3 shows the relationship between Headache, Visual fatigue, Poor posture, Migraine, Numbness in fingers, Back pain, Depression hazards and technostress level associated with auditors. Out of the 825 respondents in this study, 478 respondents recorded the headache hazard and a level of technostress. Fifty-five percent (55.0\%) 
Table 3. Percentage distribution of respondents by significant ergonomic hazards relating to level of technostress.

\begin{tabular}{|c|c|c|c|c|}
\hline \multirow{2}{*}{ Ergonomic Hazard (Intensity) } & \multicolumn{2}{|c|}{ Level of Technostress } & \multirow{2}{*}{ Total } & \multirow{2}{*}{$\chi^{2}(p-v a l u e)$} \\
\hline & Low & High & & \\
\hline \multicolumn{5}{|l|}{ Neck pain } \\
\hline High & $7(13.7 \%)$ & 44 (86.3\%) & $51(100.0 \%)$ & \multirow{5}{*}{$\begin{array}{l}12.894 \\
(0.005)\end{array}$} \\
\hline Moderate & 24 (42.9\%) & 32 (57.1\%) & $56(100.0 \%)$ & \\
\hline Low & 15 (42.9\%) & 20 (57.1\%) & $35(100.0 \%)$ & \\
\hline Non-existent & $1(50.0 \%)$ & $1(50.0 \%)$ & $2(100.0 \%)$ & \\
\hline Total & 47 (32.6\%) & 97 (67.4\%) & $144(100.0 \%)$ & \\
\hline \multicolumn{5}{|l|}{ Wrist pain } \\
\hline High & $26(45.6 \%)$ & 31 (54.4\%) & $57(100.0 \%)$ & \multirow{5}{*}{$\begin{array}{c}9.138 \\
(0.028)\end{array}$} \\
\hline Moderate & 12 (24.5\%) & 37 (75.5\%) & $49(100.0 \%)$ & \\
\hline Low & 8 (19.5\%) & 33 (80.5\%) & $41(100.0 \%)$ & \\
\hline Non-existent & $1(33.3 \%)$ & $2(66.7 \%)$ & $3(100.0 \%)$ & \\
\hline Total & 47 (31.3\%) & $103(68.7 \%)$ & $150(100.0 \%)$ & \\
\hline \multicolumn{5}{|l|}{ Inadequate sleep } \\
\hline High & 52 (39.1\%) & 81 (60.9\%) & 133 (100.0\%) & \multirow{5}{*}{$\begin{array}{c}8.276 \\
(0.041)\end{array}$} \\
\hline Moderate & $76(51.0 \%)$ & 73 (49.0\%) & 149 (100.0\%) & \\
\hline Low & $92(50.0 \%)$ & $92(50.0 \%)$ & $184(100.0 \%)$ & \\
\hline Non-existent & $3(100.0 \%)$ & Nil & $3(100.0 \%)$ & \\
\hline Total & $223(47.5 \%)$ & $246(52.5 \%)$ & 469 (100.0\%) & \\
\hline
\end{tabular}

Source: Field Survey, 2013.

of the respondents have high headache intensity with high level of technostress, $45.3 \%$ have a combination of moderate headache with high level of technostress, $47.5 \%$ recorded low headache with high level of technostress while $0.0 \%$ claimed that the combination of headache and technostress was non-existent. From the analysis, it was discovered that more of the auditors (50.6\%) recorded a low level of technostress as compared with those with the high level of technostress (49.4\%). This implies that headache hazard among auditors might be as a result of several other factors which might not be associated with the usage of technology. Table 3 also shows a breakdown of the visual fatigue hazard associated with an auditor's job. Out of the 825 respondents who participated in the study, 157 respondents recorded both the visual fatigue hazard and a level of technostress. More than seventy-four percent (74.6\%) of the respondents have high visual fatigue with high level of technostress, $62.3 \%$ have a combination of moderate visual fatigue with high level of technostress, 66.7\% recorded low intensity visual fatigue with high level of technostress while no respondent claimed the combination of non-existent visual fatigue and technostress. From the analysis, it was observed that more of the auditors (68.2\%) recorded a high level of technostress as compared with those with low level of technostress (31.8\%). This implies that visual fatigue hazard among auditors is on the high side. To find out if there is a relationship between visual fatigue hazard and the level of technostress among auditors, a Pearson's Chi-Square test was carried out at a 0.05 level of significance.

It was also observed that there was no significant relationship between poor posture as a hazard and technostress $\left(\chi^{2}=5.152 ; p=0.161\right)$, since the calculated value $(0.161)$ of the p-value of the Pearson's Chi-Square test is greater than the tabulated value (0.05). In Table 3, a breakdown of migraine hazard associated with technostress on an auditor's job is clearly shown. Out of the 825 respondents who participated in the study, 103 respondents recorded both the migraine hazard and a level of technostress. This implies that migraine hazard 
among auditors is on the high side. A Pearson's Chi-Square test was further carried out at a 0.05 level of significance to find out if there is a significant relationship between migraine hazard and the level of technostress among auditors. From Table 3, the result of the test shows that there is no significant relationship between migraine as a hazard and technostress $\left(\chi^{2}=4.905 ; p=0.179\right)$. This connotes that migraine among auditors might be as a result of other factors aside from their usage of technological facilities. The relationship between numbness in fingers and its associated level of technostress was also investigated. Of the 825 respondents in this study, 124 respondents recorded both the numbness in fingers hazard. From Table 3, the result of the test shows that there is no significant relationship between numbness in fingers as a hazard and technostress $\chi^{2}=1.241 ; p=$ 0.743). This means that numbness in fingers hazard experienced by auditors is as a result of other factors and not as a result of technology-related stress. The correlation between back pain as a hazard, and technostress is also shown in Table 3. Of the 825 respondents in this study, 139 respondents recorded both the back pain hazard and a level of technostress. More than eighty-two percent (82.5\%) of the respondents have high back pain intensity with high level of technostress, $62.0 \%$ have a combination of moderate back pain with high level of technostress, $69.0 \%$ recorded low back pain with high level of technostress while $33.3 \%$ claimed that the combination of headache and technostress was non-existent. In order to find out if there is a relationship between back pain hazards among auditors, a Pearson's Chi-Square test was carried out at a 0.05 level of significance.

From Table 3, the result of the test shows that there is a no significant relationship between depression as a hazard and technostress $\left(\chi^{2}=3.032 ; p=0.387\right)$. This connotes that depression, which could be the result of a bad sitting position, cannot lead to an increase in the level of technostress.

\subsection{Effect of Ergonomic Hazards on Performance of Auditors}

In an attempt to find out about the type of relationship that exists between ergonomic hazards and performance of auditors, a cross-tabulation was performed on these two variables. Pulling all the individual variables that constituted ergonomic hazards together, a scale was developed which was grouped into "low hazard at work", "moderate hazard at work" and "high hazard at work". The mean value for ergonomic hazards was thus calculated using SPSS statistical package, and was given as 5.0 while the standard deviation was 6.2. The minimum value that was obtained from the selection of "low hazard at work" was 0.0 while the maximum value that was obtained from the selection of "high hazard at work" was 28 . Variables which fell within the range of 0.0 and 2.0 constituted the "low hazard at work", variables which fell within the range of 2.1 and 11.0 made up the "moderate hazard at work", while variables which fell within the range of 11.1 and 28.0 constituted the "high hazard at work".

From Table 4, it is observed that a better percentage of the respondents performed satisfactorily at moderate (42.9\%) and low hazard (46.4\%) levels at work. However, a definitive pattern was not observed in this relationship and thus, a Pearson's Chi-Square test was further carried out at a 0.05 level of significance to determine

Table 4. Percentage distribution of respondents' ergonomic hazards in relationship with performance.

\begin{tabular}{|c|c|c|c|c|c|}
\hline \multirow{2}{*}{ Performance } & \multicolumn{3}{|c|}{ Hazard intensity } & \multirow{2}{*}{ Total } & \multirow{2}{*}{$\underset{\text { (p-value })}{\chi^{2}}$} \\
\hline & Low hazard at work & Moderate hazard at work & High hazard at work & & \\
\hline \multirow{2}{*}{$\begin{array}{l}\text { Unsatisfactory } \\
\text { performance }\end{array}$} & 54 & 67 & 19 & 140 & \multirow{8}{*}{$\begin{array}{c}4.764 \\
(0.312)\end{array}$} \\
\hline & $(38.6 \%)$ & (47.9\%) & $(13.6 \%)$ & $(100.0 \%)$ & \\
\hline \multirow{2}{*}{$\begin{array}{l}\text { Satisfactory } \\
\text { performance }\end{array}$} & 221 & 239 & 55 & 515 & \\
\hline & (42.9\%) & (46.4\%) & $(10.7 \%)$ & $(100.0 \%)$ & \\
\hline \multirow{2}{*}{$\begin{array}{l}\text { Outstanding } \\
\text { performance }\end{array}$} & 43 & 46 & 19 & 108 & \\
\hline & $(39.8 \%)$ & $(42.6 \%)$ & $(17.6 \%)$ & $(100.0 \%)$ & \\
\hline \multirow{2}{*}{ Total } & 318 & 352 & 93 & 763 & \\
\hline & $(41.7 \%)$ & (46.1\%) & (12.2\%) & $(100.0 \%)$ & \\
\hline
\end{tabular}

Source: Field Survey, 2013. 
the relationship between ergonomic hazards and performance among auditors. The result shows that there is no significant relationship between ergonomic hazards and performance of auditors $\left(\chi^{2}=4.764 ; p=0.312\right)$. Hence, auditors can satisfactorily perform their office tasks irrespective of the hazards they encounter within the office environment, but such performance might not be outstanding.

\section{Discussion of Findings}

This study explored the relationship between ergonomic hazards and performance within the big four auditing firms in Nigeria, which are KPMG, Akintola Williams Delloite, PwC, and E \& Y. Overall, the results indicated that technostress is on a moderate level in the organisations considered, although, some auditors experienced it on the high side on an individual level. Contrary to the original hypothesis that there is no significant relationship between technostress and ergonomic hazards, it was shown that technostress triggered hazards such as neck pain, wrist pain, and inadequate sleep, which was supported by the outcome of findings in previous literatures. An interesting finding of this study is that technostress was found not to have any correlation with headache, visual fatigue, poor posture, back pain, finger numbness, migraine or depression, which is contrary to the findings in some studies; the results were insignificant. The organization may mitigate the effect of technostress on ergonomic hazards through improving ergonomic procedures such as the provision of adjustable screens, chairs that fit table tops, provision of chair with armrests, provision of appropriate size \& shape of chairs, allowing workers to take frequent breaks when tired, and mounting display screens at appropriate angles to sitting position.

It was also discovered that the less the level of technostress, the higher the performance among the auditors, although, an insignificant relationship was revealed between these two variables. It is however important to note that reduced stress will enhance the dedication of workers within an organisation and on the overall, lead to improved performance. The contract between employers and auditors can only be of mutual benefit to both parties if there is improved corporate attention to the working conditions of the auditors. Central among these issues is offering the auditors the relief from stress associated with improved technology usage and imperative demand for the acquisition of new knowledge on such technological facilities.

As the rate of change in information system and technology increases, the solution lies not in mere laying off of employees but in better developing human resources within the organization. This can be done through the provision of adequate training for employees before the introduction of any new technology, as suggested by majority of the auditors. If employees are forced to learn the new technology on the job, there is likelihood for them to suffer from technostress which is evident from their intensity of neck pain and inadequate sleep hazards. On the other hand, employees will be more willing to accept new technology when they have been trained on how to use such a technology, and this will in turn reduce the level of technostress. This is an important implication for management of organisations to balance office coping strategies with participation mechanism in order to avoid high levels of employee technostress. As management continues the development of human resources as capital assets (Weiss, 2000), auditor will increase in value relative to the organisation's investment in them.

\subsection{Research Limitations}

The findings presented in this study must be understood within the context of the following limitations: firstly, there was difficulty in getting back some of the questionnaires administered to respondents as a result of their very tight schedules. Secondly, this study was done in private organizations only and generalization across various sectors has to be accompanied with caution. Therefore, it is suggested that subsequent research on technostress, ergonomic hazards and performance, should include public organisations for a more robust population sampling.

\subsection{Summary of Findings}

Findings from this research work revealed the following:

1) Several hazards have been found to be associated with an auditor's job and top on the list of the hazards is headache, as opined by $56.9 \%$ of the respondents. More than fifty-four percent (54.5\%) of the respondents also reported inadequate sleep. Low on the list were visual fatigue (16.9\%), back pain (15.9\%), neck pain (15.2\%), wrist pain (15.0\%), numbness in finger (12.1\%), poor posture (11.7\%), migraine (10.4\%), and depression (8.5\%). 
2) These hazards were claimed to be caused by improper ergonomic procedures such as poor lighting in office areas, poor screen resolution, poor screen positioning, inability to adjust monitor, and inability to adjust chair height in the most appropriate angle. Others are difficulty to copy materials from the screen, lack of ability to take frequent breaks when tired, inability to use mouse pad while working on the computer, provision of chair without armrests, inappropriate size and shape of chair, and display screen being too close to sitting position.

3) It was discovered that neck pain $\left(\chi^{2}=12.894 ; p<0.05\right)$, wrist pain $\left(\chi^{2}=9.138 ; p<0.05\right)$, and inadequate sleep $\left(\chi^{2}=8.276 ; p<0.05\right)$ were more prevailing ergonomic hazard.

4) It was also discovered that headache $\left(\chi^{2}=4.345 ; p=0.227\right)$, visual fatigue $\left(\chi^{2}=2.206\right.$; $\left.p=0.332\right)$, poor posture $\left(\chi^{2}=5.152 ; p=0.161\right)$, back pain $\left(\chi^{2}=7.758 ; p=0.051\right)$, finger numbness $\left(\chi^{2}=1.241 ; p=0.743\right)$, migraine $\left(\chi^{2}=4.905 ; p=0.179\right)$, and depression $\left(\chi^{2}=3.032 ; p=0.387\right)$ were not significant hazards to auditors performance.

\section{Conclusion}

This study was conducted to empirically investigate issues that might be related to the key determinants of performance among auditors in their use of technological facilities. The intent was to provide insights into organisational performance by considering the influence of technostress and ergonomic hazards as variable in the determinant of performance within audit organisations. The analysis in this study reveals that there is much difference in the way individual auditors are affected by the issues of technostress and ergonomic hazards, and how these variables impact on the organisation in its entirety. In all the organisations considered on the whole, it was revealed that an insignificant relationship exists between level of technostress and performance and between ergonomic hazards and performance within audit firms, although, individual assessment gave significant relationships on some ergonomic hazards. Hence, perceptions of the technological stress on performance are still somewhat ambiguous, since some individuals can cope better than their other colleagues. It can however be concluded that overall performance can better be improved if technological facilities coping strategies and working conditions are improved within organisations. The results of this study would be useful to organisations that make daily use of information communication technologies and have been trying to address the issues of technostress and ergonomic hazards from a different perspective. It will also help managers to formulate the best coping strategy by striking a balance between technology usage and level of technostress in order to alleviate it to the barest minimum. The contemporary global world is a very stressful one with demands and changes to grapple with. As technology is here to stay, it is crucial we appreciate the different responses to it, as well as fashion out adaptable ways of adjusting to it.

\subsection{Recommendations}

Considering the ramifications of technology usage among auditors, management of such organisations need to focus on strategies and plans that will produce a dynamic work environment for its employees for utmost performance. They must take practical measures to provide adequate coping strategies to new technologies and the conducive environment to its employees. As presented in this study, technology is instrumental to an auditor's job, yet some significant areas need to be looked into by management. Recommendations for improvement in these areas are:

1) In order to maintain a skilled workforce, employees must be provided with training in technological facilities usage as it concerns their job description. Management should hence design and implement training curricula that will empower auditors with the skills and abilities to make them cope with changing technology.

2) Management should provide timely technical support and regular upgrading of equipment and software.

3) Management should involve staff in choosing and integrating technology into work processes and practices which will encourage participative management.

\subsection{Suggestion for Future Research}

Results from this study indicate several areas where future research will have positive implications on technostress-ergonomic hazards-performance relationships. One area for further research might be to conduct the study using a larger sample and a broader geographical base. Another possibility is to replicate the study to include 
other types of personnel such as academics and non-academics, to facilitate a comparative analysis. Finally, there is a need to re-examine and re-validate a uniform measure of technostress and ergonomic hazards for information professionals. Little research has been carried out in this area and such an instrument would identify the sources of technostress, thus contributing to the development of appropriate strategies for the integration of technology into the work environment. Researchers could use the instrument to examine differences among information professionals according to gender, level of education, and area of work.

\section{References}

[1] Fisher, W. and Wesolkowski, S. (1999) Tempering Technostress. Technology and Society Magazine, 18, $28-33$. http://dx.doi.org/10.1109/44.752243

[2] Brod, C. (1984) Technostress: The Human Cost of the Computer Revolution. Addison-Wesley Publishing Company, Reading.

[3] Kupersmith, J. (1992) Technostress and the Reference Librarian. Reference Services Review, 20, 7-14, 50. http://dx.doi.org/10.1108/eb049150

[4] Tarafdar, M., Tu, Q., Ragu-Nathan, B.S. and Ragu-Nathan, T.S. (2007) The Impact of Technostress on Role Stress and Productivity, Journal of Information Management Systems, 24, 301-328. http://www.jmis-web.org/articles/v24_n1_p301/index.html

[5] Chauhan, T. S. (2003) RSI Placing a Strain on Workplace. Canadian Medical Association Journal, 169, 1203.

[6] De Kraker, H. and Blatter, B.M. (2005) Prevalentiecijfers van RSI-klachten en het voorkomen van riscicofactoren in 15 Europeselanden. Tijdschrift Scoiale Geneeskunde, 83, 8-15.

[7] Mak, B., Sockel, H., Bucholz, J.A. and Webb, M.W. (2010) Technostress and Organization Loyalty of IS \& T Workers-A Path Model. International Journal of Information Processing and Management, 1, 4-17. http://dx.doi.org/10.4156/ijipm.vol1.issue2.1

[8] Yu, J.C., Kuo, L.H., Chen, L.M., Yang, H.J., Yang, H.H. and Hu, W.C. (2009) Assessing and Managing Mobile Technostress. WSEAS Transactions on Communications, 8, 1-1

[9] Liu, Y. and Wang, K. (2011) Technostress of IT Professionals: Diverse for Different Personality Type and Related to Different Career Orientations. Proceedings of the 5th China Summer Workshop on Information Management (CSWIM), Harbin.

[10] Bichteler, J. (1987) Technostress in Libraries: Causes, Effects, and Solutions. The Electronic Library, 5, 282-287. http://dx.doi.org/10.1108/eb044766

[11] Clark, K. and Kalin, S. (1996) Technostressed out? How to Cope in the Digital Age. Library Journal, 121, 30-32.

[12] Pitkin, G.M. (1997) Technostress in Libraryland. Colorado Libraries, 23, 58-61.

[13] Harper, S. (2000) Managing Technostress in UK Libraries: A Realistic Guide. Ariadne, 25. http://www.ariadne.ac.uk/issue25/technostress

[14] Gorman, M. (2001) Technostress and Library Values. Library Journal, 126, 48-50.

[15] Kupersmith, J. (2005) Library Technostress Survey Results. http://www.jkup.net/stress-survey-2003.html

[16] Ungku, N.U.A., Salmiah, M.A. and Wan, K.W.I. (2009) The Impact of Technostress on Organisational Commitment among Malaysian Academic Librarians. Singapore Journal of Library and Information Management, 38, 103-123.

[17] Ragu-Nathan, T.S., Tarafdar, M., Ragu-Nathan, B.S. and Tu, Q. (2008) The Consequences of Technostress for End Users in Organizations: Conceptual Development and Empirical Validation. Information Systems Research, 19, 417433. http://dx.doi.org/10.1287/isre.1070.0165

[18] Abugabah, A.J., Sanzogni, L. and Poropat, A.E. (2009) The Impact of Information Systems On User Performance: A Critical Review and Theoretical Model. World Academy of Science, Engineering and Technology, 57, 809-819.

[19] Tiwari, T., Singh, A.L. and Singh, I.L. (2008) Information Technology-Induced Stress and Human Performance: A Critical Review. Journal of the Indian Academy of Applied Psychology, 34, 241-249.

[20] Baumeister, R.F. and Showers, C.J. (1986) A Review of Paradoxical Performance Effects: Choking Under Pressure in Sports and Mental Tests. European Journal of Social Psychology, 16, 361-383. http://dx.doi.org/10.1002/ejsp.2420160405

[21] Chi, H.K., Yeh, H.R. and Chiou, C.-Y. (2008) The Mediating Effects of Internal Marketing on Transformational Leadership and Job Performance of Insurance Salespersons in Taiwan. The Business Review, 11, 173-180.

[22] Kalbers, L.P. and Cenker, W.J. (2008) The Impact of Exercised Responsibility, Experience, Autonomy, and Role Ambiguity on Job Performance in Public Accounting. Journal of Managerial Issues, 20, 327-347. 
[23] Fisher, R.T. (2001) Role Stress, the Type A Behavior Pattern, and External Auditor Job Satisfaction and Performance. Behavioral Research in Accounting, 13, 143-170. http://dx.doi.org/10.2308/bria.2001.13.1.143

[24] Christodoulou, M. (2011) UK Auditors Braced for Report Examining Role in Banking Crisis. Wall Street Journal, 8, 15.

[25] Elliot, R.K. (2002) Twenty-First Century Assurance. AUDITING: A Journal of Practice and Theory, 21, 139-146. http://dx.doi.org/10.2308/aud.2002.21.1.139

[26] Scapens, R.W. and Jazayeri, M. (2003) ERP Systems and Management Accounting Change: Opportunities or Impacts? A Research Note. European Accounting Review, 12, 201-233. http://dx.doi.org/10.1080/0963818031000087907

[27] Winograd, B.N., Gerson, J.S. and Berlin, B.L. (2000) Audit Practices of PricewaterhouseCoopers. AUDITING: A Journal of Practice and Theory, 19, 176-182. http://dx.doi.org/10.2308/aud.2000.19.2.176

[28] Janvrin, D., Bierstaker, J. and Lowe, D.J. (2008) An Examination of Audit Information Technology Use and Perceived Importance. Accounting Horizons, 22, 1-21. http://dx.doi.org/10.2308/acch.2008.22.1.1

[29] Choo, F. (1986) Job Stress, Job Performance and Auditor Personality Characteristics. AUDITING: A Journal of Practice and Theory, 5, 17-34.

[30] Dolhy, A. (2006) Small Workplace Ergonomics Resource Guide. MFL Occupational Health Centre Inc., Broadway, 102-275.

[31] Mvungi, V.P., Mcharo, J., Mmbuji, M.E., Mgonja, L.E. and Kitua, A.Y. (2008) Health Hazards Related to Computer Use: Experience of the National Institute for Medical Research in Tanzania. World Academy of Science, Engineering and Technology, 48, 474-479. 